\title{
Planned Inclusion Criterion
}

National Cancer Institute

\section{Source}

National Cancer Institute. Planned Inclusion Criterion. NCI Thesaurus. Code C162664.

An activity that is intended to occur at some point in the context of a particular study that represents a characteristic or requirement intended to be applied to a potential study subject to determine whether they may participate in a study. 